\title{
The use of microwave radiometer data for characterizing snow storage in western Ghina
}

\author{
A. T. C. Chang, J. L. Foster, D. K. Hall, \\ Hydrological Sciences Branch, NASA Goddard Space Flight Center, Greenbelt, Maryland, U.S.A. \\ D. A. Robinson, \\ Department of Geography, Rutgers University, New Brunswick, New Jersey, U.S.A. \\ Li Peiji and Cao Meisheng \\ Lanzhou Institute of Glaciology and Geocryology, Academia Sinica, Lanzhou 730000, China
}

\begin{abstract}
In this study a new microwave snow retrieval algorithm was developed to account for the effects of atmospheric emission on microwave radiation over high-elevation land areas. This resulted in improved estimates of snow-covered area in western China when compared with the meteorological station data and with snow maps derived from visible imagery from the Defense Meteorological Satellite Program satellite. Some improvement in snow-depth estimation was also achieved, but a useful level of accuracy will require additional modifications tested against more extensive ground data.
\end{abstract}

\section{INTRODUGTION}

In areas of high mountains, where snowmelt runoff makes up a large portion of the water supply, snow-cover and snow-storage information are vital for management of water resources. "In western China, the varying snow extent and storage may influence the Asian summer monsoon and be linked to summer precipitation in southeastern China (Barnett and others, 1989; Hahn and Shukla, 1976). Up to now, empirical studies and climate models have fallen short of producing conclusive evidence for this because of limited or unreliable snow data. To understand better the possible teleconnection between snow, weather and climate in western China, more accurate and reliable snow data are needed.

The most reliable snowpack parameter that can be extracted using satellite data is the area covered by snow. The availability of these data is somewhat limited, however, because of frequent cloud cover over large basins. Short-wavelength sensors cannot provide adequate information on the depth and water equivalent of the snowpack, which is needed to improve further our understanding of climatological processes and snowmelt runoff predictions.

Microwave radiation, which is not strongly affected by cloud cover, has the capability of penetrating the snowpack. This portion of the electromagnetic spectrum can provide information about the thickness of the snow and has been used for monitoring snowpack storage in homogeneous areas with some success (Rango and others, 1979; Kunzi and others, 1982; Chang and others, 1987).
In the present study an algorithm was developed to account for the effect of atmospheric constituents on microwave radiation emerging from a snowpack. This resulted in improved snow-depth estimates when compared with meteorological station data.

\section{MICROWAVE EMISSION FROM SNOW}

Microwave emission from a layer of snow over ground consists of two parts: emission by the underlying ground and emission/scattering by the snow itself. Both of these contributions are governed by the transmission and the reflection properties of the air-snow and snow-ground interfaces, and by the absorption and scattering properties of the snow layer. A snowpack can be modelled either as a collection of scatterers distributed within a dielectric medium (Chang and others, 1976) or as a continuous random medium with dielectric variation (Tsang and Kong, 1981). In this paper the method developed by Chang and others (1976) will be used to explain the radiative processes within the snowpack. Snow crystals act as scattering centers for microwave radiation passing through a snowpack. The energy scattered by snow particles, which redistributes the upwelling ground radiation according to the snow density, thickness, and crystal size, provides the physical basis for microwave detection of snow. Theoretical computations indicate that at $37 \mathrm{GHz}(\lambda=0.8 \mathrm{~cm})$ radiation within a dry snowpack is affected predominantly by the scattering of snow crystals. The effective microwave penetration depth into 
a dry snowpack, typically 10 to 100 wavelengths, depends on the wavelength used and the characteristic crystal size of the snowpack.

The Nimbus-7 Scanning Multichannel Microwave Radiometer (SMMR) is a five-frequency, dual-polarized microwave radiometer which measures the upwelling microwave radiation at $6.6,10.7,18.0,21.0$ and $37.0 \mathrm{GHz}(4.6,2.8,1.7,1.4$ and $0.8 \mathrm{~cm})$ while scanning $25^{\circ}$ to either side of the spacecraft (swath width approximately $780 \mathrm{~km}$ ) with a constant incidence angle of approximately $50^{\circ}$ with respect to the Earth's surface. The spatial resolution at $37 \mathrm{GHz}(\lambda=0.8 \mathrm{~cm})$ is about $25 \mathrm{~km}$ and at $18 \mathrm{GHz}(\lambda=1.7 \mathrm{~cm})$ about $50 \mathrm{~km}$. Since October 1978 and until August 1987 the SMMR has been acquiring passive microwave data which have been used for monitoring snow-cover characteristics.

\section{SNOW-PARAMETER RETRIEVAL ALGORITHM}

Several years ago, a snow water equivalent retrieval algorithm based on the differences between the microwave brightness temperature at 37 and $18 \mathrm{GHz}$ was developed (Chang and others, 1987). For uniform snow fields the algorithm can be written as:

$$
S W E=0.48 \times\left(T_{18 \mathrm{H}}-T_{37 \mathrm{H}}\right) \mathrm{cm}
$$

where $S W E$ is the snow water equivalent in $\mathrm{cm}$, and $\tau_{18 \mathrm{H}}$ and $T_{37 \mathrm{H}}$ are the horizontally polarized brightness temperature for the SMMR $18 \mathrm{GHz}$ and $37 \mathrm{GHz}$ radiometers. This algorithm is based on a regression relationship derived from theoretically calculated brightness temperatures for a layer of snow of varying depth (up to $100 \mathrm{~cm}$ ) and density above frozen soil. The offset term of the linear fit between $S W E$ and brightness temperature difference is zero in this case. A more detailed description of this model can be found in Chang and others (1987). This algorithm has been used to derive global snow maps using Nimbus-7 SMMR data from 1978 to 1987 (Chang and others, 1987). The effects of atmospheric components on the brightness temperature differences were not included in the original calculations. Also, any calibration errors associated with the brightness temperatures were absorbed into the intercept term of Equation (1). Reanalysis of Canadian data (Rango and others, 1979) shows that this algorithm has a tendency to overestimate the thickness of shallow snowpacks and underestimate deep snowpacks. Since the only ground data available for this study are measurements of snow depth, the relationship in Equation (1) has been modified for snow depth having a constant snow density and can be written as:

$$
S D=1.59 \times\left(T_{18 \mathrm{H}}-T_{37 \mathrm{H}}\right) \mathrm{cm} .
$$

When applying this equation to western China, many discrepancies in the snow maps have been noticed. This is probably due to the fact that (1) the assumed snow density $\left(0.3 \mathrm{~g} \mathrm{~cm}^{3}\right)$ and mean snow-grain radius $(0.3 \mathrm{~mm})$ are different from those in western China, and (2) Equation (2) was tuned for a uniform snow field with moderate snow depth. The assumed snow density and snow-grain radius are the averaged values for many snow pits from the Colorado River basin (unpublished field data). Over western China, snow cover is predominantly shallow, patchy, and frequently of short duration (Li, 1987). In addition, Equation (2) was tuned for lowelevation regions. Because western China is a mountainous, arid, and high-altitude region, atmospheric effects are major complicating factors to the existing algorithm. The shallow snow cover in this region makes interpretation more difficult, since passive microwave sensors have trouble detecting patchy dry snow less than about $5 \mathrm{~cm}$ deep. Thus, it is necessary to adjust Equation (2) and recalibrate the SMMR estimates with ground station data and visible imagery from the Defense Meteorological Satellite Program (DMSP) satellite.

\section{COMPARISONS OF SMMR SNOW PRODUCTS WITH DMSP AND STATION DATA}

Daily snow depth reported by 175 weather stations for two of the winters (1978-79 and 1979-80) were used for comparison with the satellite-derived snow data. A major limitation of the meteorological station data in western China is the uneven distribution of the stations in Tibet and in high mountainous areas. Therefore, station data integrated with visible DMSP data were used as "ground truth" by which microwave data were calibrated.

The DMSP Operational Linescan System (OLS) is a broad-band sensor with wavelengths in the visible range from about 0.4 to $1.1 \mu \mathrm{m}$ and a spatial resolution of about $0.6 \mathrm{~km}$. In this study, $9^{\prime \prime} \times 9^{\prime \prime}$ hard copies of visible DMSP archived imagery were analyzed and interpreted visually by trained analysts for one degree latitude and one degree longitude grids. This was the finest grid feasible with the imagery available. Five categories that were generated are:

(1) patchy, 10 to $30 \%$ snow cover,

(2) medium, 20 to $80 \%$ snow cover,

(3) bright, 80 to $100 \%$ snow cover,

(4) snow free, $<10 \%$ snow cover, and

(5) cloud.

The SMMR derived snow maps for the period of 1978-1987, with areal coverage between 70 to $100^{\circ} \mathrm{E}$

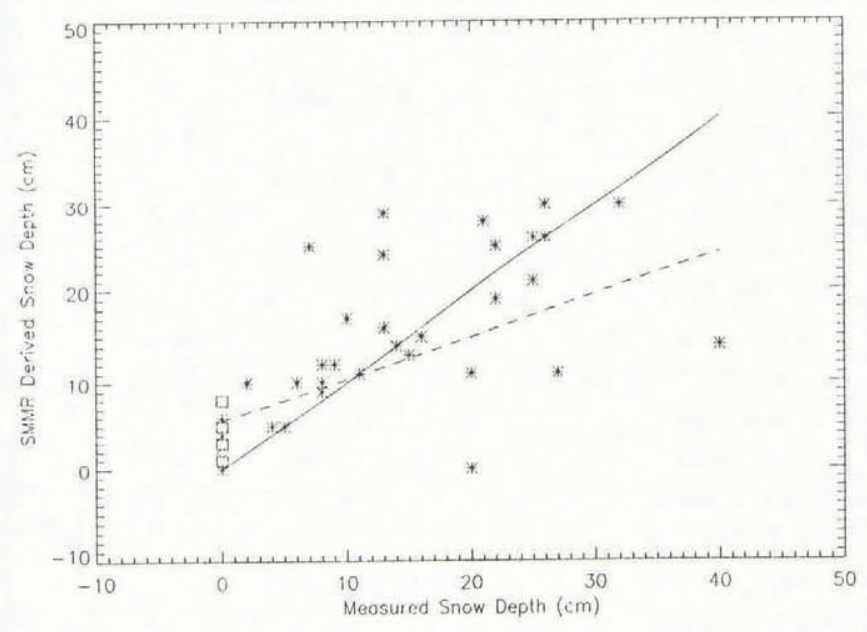

Fig. 1. Scatter plot of SMMR-derived snow depth using Equation (2) versus station data. The dashed line is the regression line, the solid line is the $1: 1$ line. Stars represent single data points, squares represent two data points, and the diamond represents three data points. 

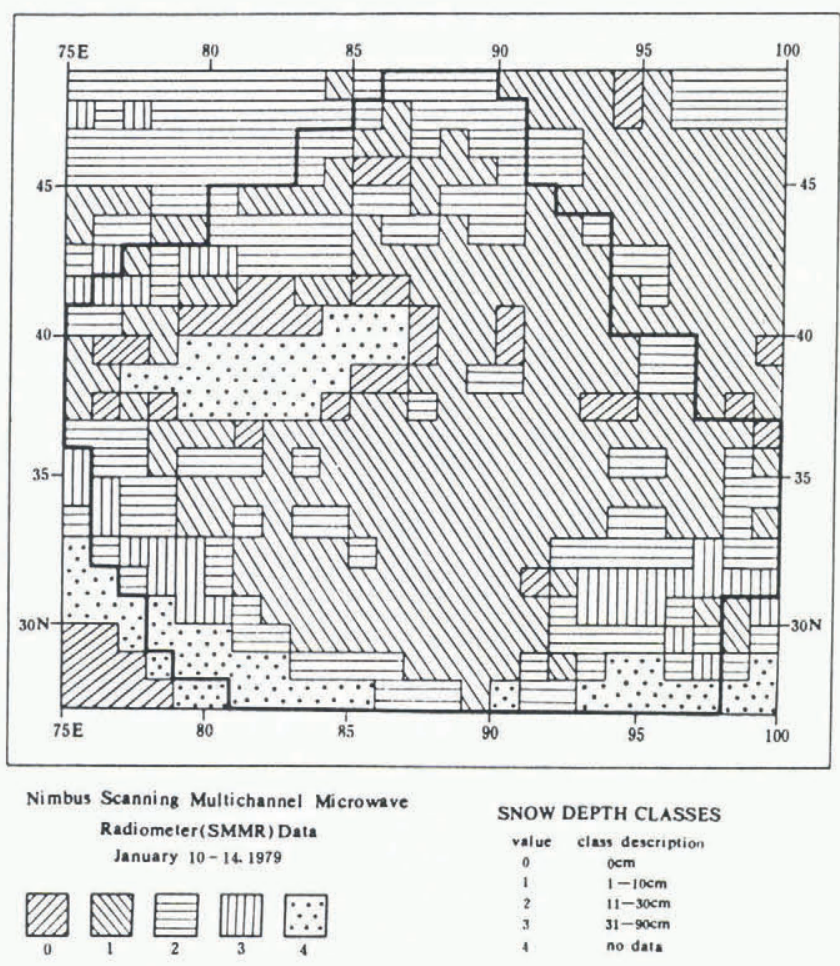

Fig. 2. SMMR-derived snow-depth class map, Equation (2), 10-14 January 1979.

longitude and 25 to $50^{\circ} \mathrm{N}$ latitude, were used for comparison. SMMR-derived microwave snow depths are mapped onto $1 / 2^{\circ}$ by $1 / 2^{\circ}$ grid cells over a five-day period. Comparisons between the station data and SMMR data revealed that SMMR-derived snow values tend to overestimate shallow snowpacks and underestimate deep snowpacks (Fig. 1). Furthermore, comparison of the SMMR-derived snow depths (Fig. 2), the DMSP snow class map (Fig. 3), and the station snow map (Fig. 4) demonstrates that not only snow depth but also snow areas from SMMR greatly exceed values from visible imagery and ground station reports. Comparisons between the percentage of snow-cover extent derived from the SMMR and the DMSP data are shown in Table 1. The visible DMSP data, being easy to interpret, are used as the reference. They reveal that considerable differences exist in the accuracy for different physiographic regions. SMMR data overestimated snow cover in the plateau area and high mountains, but snow-cover estimates were more accurate in the low mountains, rolling hills, and basins. SMMR products severely overestimated snow-covered area during the months of November and March, which are the cold-season months, usually having the least snow cover. In spring, when the snow is wet, the SMMR algorithm underestimates the snow depth (Stiles and Ulaby, 1980).

\section{ALGORITHM REVISION}

In order to circumvent the problems described above, a revised model has been adopted to account for atmospheric effects. A mid-latitude, winter, standard atmosphere without clouds was superimposed above the snow

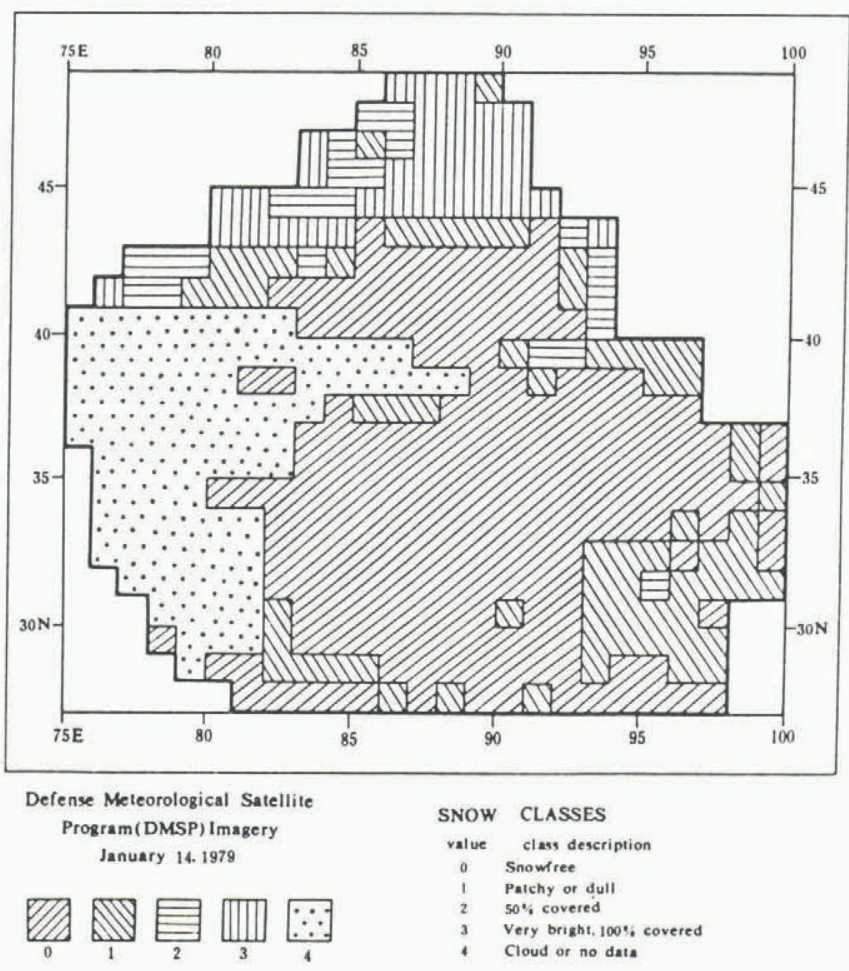

Fig. 3. DMSP-derived snow-class map, 14 January 1979.

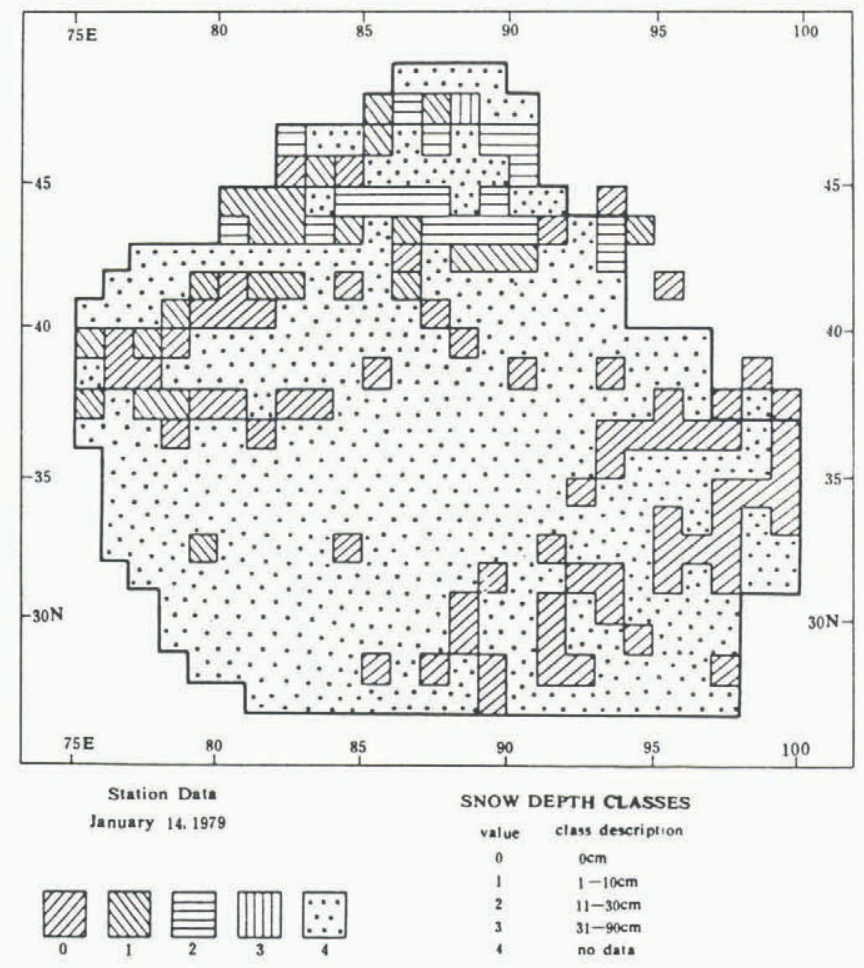

Fig. 4. Snow-depth class map from station data, 14 January 1979.

layer to calculate the brightness temperatures. The newly calculated brightness temperature-snow-depth relationship can be expressed as:

$$
S D=2.0 \times\left(T_{18 \mathrm{H}}-T_{37 \mathrm{H}}\right)-8.0 \mathrm{~cm},
$$

where 2.0 is the slope and -8.0 is the intercept. The slope of Equation (3) is slightly larger than that of Equation 
Chang and others: Snow cover estimated from microwave data

Table 1. Comparison of DMSP and SMMR data in different physiographic regions of western China

Percentage of snow cover

$\begin{array}{cccc}\text { Plateau } & \text { High } & \text { Low } & \text { Rolling } \\ \text { mountains } & \text { mountains } & \text { hills } & \text { Basins }\end{array}$

$\begin{array}{lcccccccccc}\text { Monthlyear } & \text { DMSP } & \text { SMMR } & \text { DMSP } & \text { SMMR } & \text { DMSP } & \text { SMMR } & \text { DMSP } & \text { SMMR } & \text { DMSP } & \text { SMMR } \\ \text { Jan 79 } & 20.9 & 84.9 & 39.8 & 86.4 & 60.2 & 56.5 & 46.2 & 50.0 & 19.7 & 20.9 \\ \text { Jan 80 } & 36.8 & 89.5 & 51.8 & 93.5 & 55.0 & 58.7 & 46.2 & 58.3 & 22.5 & 23.2 \\ \text { Jan 85 } & 68.0 & 87.8 & 66.0 & 81.3 & 73.0 & 66.3 & 57.7 & 70.8 & 46.5 & 31.1 \\ \text { Jan 86 } & 83.2 & 93.7 & 95.2 & 92.4 & 64.5 & 70.3 & 38.0 & 50.0 & 19.7 & 31.0 \\ \text { Jan 87 } & 71.8 & 99.1 & 78.3 & 94.0 & 74.0 & 64.4 & 80.8 & 53.9 & 23.9 & 33.8 \\ \text { Mar 79 } & 53.5 & 83.9 & 56.6 & 91.5 & 49.6 & 62.6 & 46.2 & 65.4 & 18.3 & 27.1 \\ \text { Mar 80 } & 25.0 & 81.5 & 47.0 & 81.7 & 53.0 & 62.0 & 30.8 & 60.0 & 18.1 & 24.3 \\ \text { Mar 85 } & 45.1 & 71.3 & 37.0 & 70.0 & 68.8 & 62.2 & 53.9 & 61.5 & 33.8 & 24.0 \\ \text { Mar 86 } & 65.1 & 87.0 & 78.0 & 78.1 & 62.4 & 55.4 & 32.0 & 46.2 & 8.6 & 19.1 \\ \text { Mar 87 } & 68.1 & 92.1 & 78.0 & 80.5 & 74.0 & 58.7 & 50.0 & 68.0 & 29.6 & 22.8 \\ \text { Nov 78 } & 59.1 & 79.6 & 70.3 & 81.1 & 51.7 & 27.6 & 36.4 & 36.4 & 0.0 & 3.7 \\ \text { Nov 79 } & 17.6 & 81.6 & 30.0 & 89.7 & 52.0 & 55.1 & 50.0 & 36.0 & 19.7 & 18.8 \\ \text { Nov 84 } & 60.6 & 85.5 & 69.0 & 76.0 & 45.0 & 43.8 & 12.0 & 19.2 & 17.0 & 9.9 \\ \text { Nov 85 } & 79.5 & 91.9 & 92.8 & 89.0 & 50.5 & 47.3 & 19.3 & 30.8 & 2.0 & 9.9 \\ \text { Nov 86 } & 72.7 & 92.2 & 72.0 & 82.3 & 50.0 & 32.6 & 23.0 & 11.5 & 8.0 & 5.6 \\ \text { Average } & 55.1 & 86.8 & 64.1 & 84.5 & 58.9 & 54.9 & 41.5 & 47.9 & 19.2 & 20.3\end{array}$

(2) due to the atmospheric corrections. Figure 5 shows that Equation (3) reflects the actual snow signatures measured by the SMMR more closely. The slope of the regression line between the estimated and observed snow depth is closer to the $1: 1$ line, compared with the slope derived by using Equation (2). The correlation coefficient is 0.71 . The snow depths below $10 \mathrm{~cm}$ are more evenly distributed above and below the $1: 1$ line. The mean error of estimated snow depth improved slightly to $4.7 \mathrm{~cm}$.

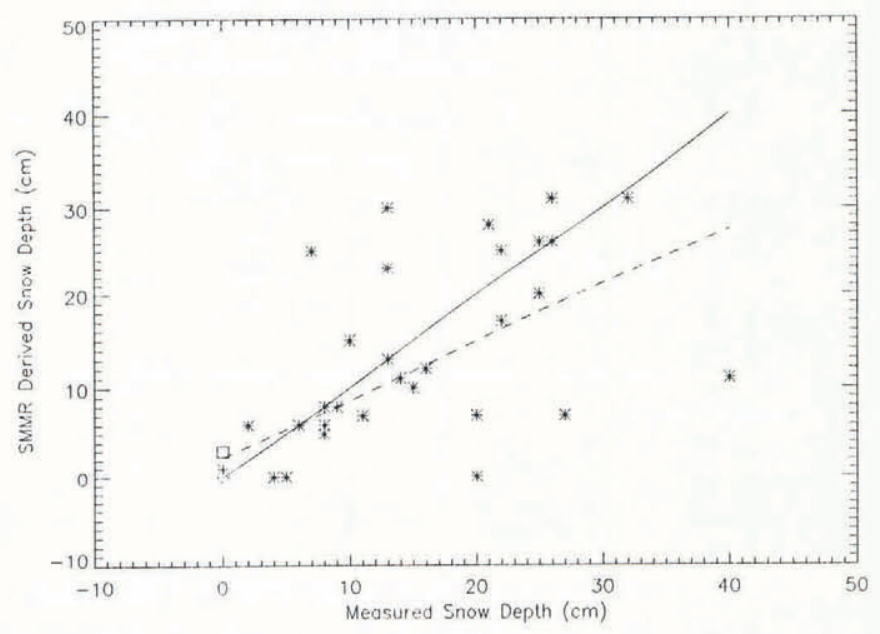

Fig. 5. Scatter plot of SMMR-derived snow depth using Equation (3) versus station data. The dashed line is the regression line, the solid line is the $1: 1$ line. Stars represent single data points, squares represent two data points, and the diamond represents 11 data points.
The adjusted SMMR snow-area map (Fig. 6) can be compared with the DMSP map (Fig. 3) and the station map (Fig. 4). Results from the comparison between adjusted SMMR snow maps and DMSP snow maps are

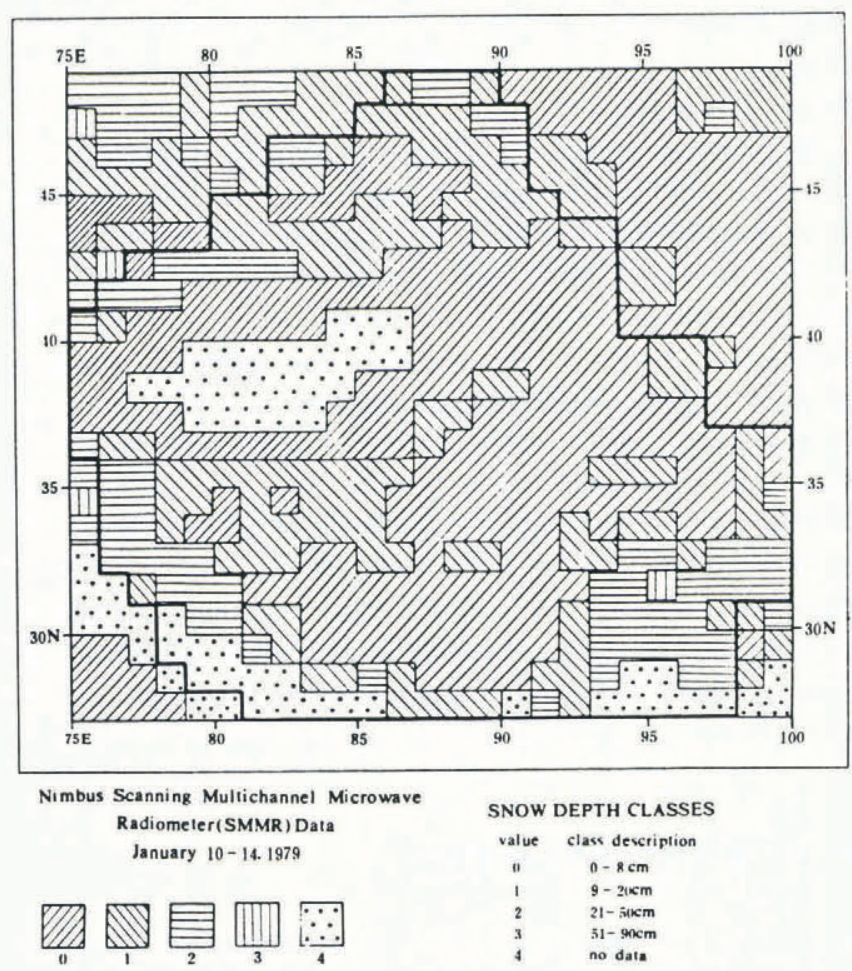

Fig. 6. SMMR-derived snow-depth class map, Equation (3), 10-14 January 1979. 
Table 2. Comparison of adjusted SMMR snow-cover area with DMSP data on the Tibet Plateau and in the high mountains

Percentage of snow cover

$$
\text { Plateau High mountains }
$$

\begin{tabular}{lrrrr} 
Monthlyear & DMSP & SMMR & DMSP & SMMR \\
& & & & \\
Jan 79 & 20.9 & 52.1 & 39.8 & 67.9 \\
Jan 80 & 36.8 & 60.5 & 51.8 & 76.6 \\
Jan 85 & 68.0 & 36.5 & 66.0 & 52.5 \\
Jan 86 & 83.2 & 72.3 & 95.2 & 78.5 \\
Jan 87 & 71.8 & 70.6 & 78.3 & 74.7 \\
Mar 79 & 53.5 & 50.0 & 56.6 & 62.2 \\
Mar 80 & 25.0 & 48.2 & 47.0 & 68.4 \\
Mar 85 & 45.1 & 24.1 & 37.0 & 38.8 \\
Mar 86 & 65.1 & 54.1 & 78.0 & 61.0 \\
Mar 87 & 68.1 & 57.1 & 78.0 & 53.3 \\
Nov 78 & 59.1 & 35.2 & 70.3 & 56.8 \\
Nov 79 & 17.6 & 51.8 & 30.0 & 73.1 \\
Nov 84 & 60.6 & 41.8 & 69.0 & 51.9 \\
Nov 85 & 79.5 & 73.0 & 92.8 & 81.7 \\
Nov 86 & 72.7 & 64.7 & 72.0 & 58.2 \\
& & & & \\
Average & 55.1 & 53.0 & 64.1 & 63.7 \\
& & & & \\
\hline
\end{tabular}

summarized in Table 2. The differences in estimated percentage of snow cover for the plateau and highmountain categories are greatly reduced. For plateau areas the averaged percentage of snow cover from Equation (2) is $86.8 \%$, and, from Equation (3), it is $53 \%$. This new value is much closer to the DMSP estimated percentage of $55.1 \%$. For high mountains, the averaged SMMR percentage changed from $84.5 \%$ to $63.7 \%$ as compared to the DMSP value of $64.1 \%$. By applying the new algorithm, the SMMR-derived snow depth and snow-covered area estimates correspond much better with the "ground truth" data.

\section{DISCUSSION}

Microwave signatures received by spaceborne sensors are not only affected by atmospheric constituents but also by surface properties, such as soil condition, vegetation cover, and topographic conditions, as well as the condition of the snow. Although the SMMR-derived snow depths for shallow snow from the adjusted algorithm compare more favorably with observed values, more work needs to be done to include snow-density and grain-size data which may further improve the performance of this algorithm. Additionally, more studies will be performed to characterize the slope and intercept of the new algorithm for different snow conditions and physiographic regions.

\section{AGKNOWLEDGEMENTS}

The snow research activities (A. T. C. Chang, J. L. Foster and D. K. Hall) at NASA/GSFC are supported by the NASA Hydrology Program. Authors from Rutgers University (D. A. Robinson) and the Lanzhou Institute of Glaciology and Geocryology (P.J. Li and M. S. Cao) wish to express their deep appreciation to the National Science Foundations of the U.S.A. and China for supporting this cooperative project through grants INT 87-13878 and 4880019 respectively.

\section{REFERENCES}

Barnett, T. P., L. Dumenil, U. Schlese, E. Roeckner and M. Latif. 1989. The effect of Eurasian snow cover on regional and global climate variations. F. Atmos. Sci., 46, 661-685.

Chang, A. T. C., P. Gloerson, T. Schmugge, T. T. Wilheit and H.J. Zwally. 1976. Microwave emission from snow and glacier ice. F. Glaciol., 16(74), 23-29.

Chang, A.T.C., J.L. Foster and D. K. Hall. 1987. Nimbus-7 SMMR derived global snow cover parameters. Ann. Glaciol., 9, 39-44.

Hahn, D. G. and J. Shukla. 1976. An apparent relationship between Eurasian snow cover and Indian monsoon rainfall. J. Atmos. Sci., 33, 2461-2462.

Kunzi, K. F., S. Patil and H. Rott. 1982. Snow-cover parameters retrieved from Nimbus-7 Scanning Multichannel Microwave Radiometer (SMMR) data. IEEE Trans. Geosci. Remote Sensing, GE20(4), 452-467.

Li Peiji. 1987. Seasonal snow resources and their fluctuations in China. International Association of Hydrological Sciences Publication 166 (Symposium at Vancouver 1987 - Large Scale Effects of Seasonal Snow Cover), 93-104.

Rango, A., A. T. C. Chang and J. L. Foster. 1979. The utilization of spaceborne microwave radiometers for monitoring snowpack properties. Nord. Hydrol., 10(1), 25-40.

Stiles, W.H. and F.T. Ulaby. 1980. The active and passive microwave response to snow parameters. I. Wetness. F. Geophys. Res., 85(C2), 1037-1044.

Tsang, L. and J.A. Kong. 1981. Scattering of electromagnetic waves from random media with strong permittivity fluctuations. Radio Sci., 16, 303-320.

The accuracy of references in the text and in this list is the responsibility of the author/s, to whom queries should be addressed. 